\title{
GENTRIFICATION OF ETHNIC BUSINESSES IN TORONTO'S LITTLE INDIA: AN ANALYSIS OF ETHNIC BUSINESS DEVELOPMENT
}

By

Taraneh Etemadi, Honours B.A., McMaster University, 2014

\author{
A Major Research Paper \\ presented to Ryerson University
}

in partial fulfillment of the requirements for the degree of

Master of Arts

in the Program of

Immigration and Settlement Studies

Toronto, Ontario, Canada 2015

CTaraneh Etemadi 2015 


\section{Author's Declaration}

I hereby declare that I am the sole author of this major research paper.

I authorize Ryerson University to lend this MRP to other institutions or individuals for the purpose of scholarly research

I further authorize Ryerson University to reproduce this MRP by photocopying or by other means, in total or in part, at the request of other institutions or individuals for the purpose of scholarly research.

I understand that my MRP may be made electronically available to the public.

Taraneh Etemadi 


\title{
GENTRIFICATION OF ETHNIC BUSINESSES IN TORONTO'S LITTLE INDIA: AN ANALYSIS OF ETHNIC BUSINESS DEVELOPMENT
}

CTaraneh Etemadi 2015

Master of Arts

Immigration and Settlement Studies

Ryerson University

\begin{abstract}
Gentrification of ethnic businesses within ethnic economies is a new phenomenon that is vastly affecting Toronto's Little India. As a result, research focusing on this issue and analysis on the way in which ethnic businesses have been developed is an important problem to investigate. This research will focus on three main research questions; observing the different looks, practices, styles, and tastes prevalent amongst restaurants in Little India, examining if the styles and tastes projected by restaurants' ethnic habitus have an impact on how ethnic businesses fare, and assessing if entrepreneurs are able or unable to modify their business practices, and styles. The analysis will be conducted through the lens of the Habitus (Bourdieu, 1987) as a theoretical framework, specifically examining the ways in which self-employed migrants develop their businesses and the role that their ethnic background and culture may have in this process. This research will take an ethnographic methodological approach in conducting the research through two steps, beginning with a naturalistic observation of two restaurants and following up with interviews. The findings determined that slight changes made to the business approach and cultural habitus of ethnic businesses can prove successful in attracting the needs of the surrounding clientele and the gentrifying population. Keywords: gentrification, South Asian, Little India, ethnic economy, self-employed migrants
\end{abstract}




\section{Acknowledgements}

The author would like to acknowledge the efforts of many people that helped in the process of completing this project:

I would like to thank Dr. Harald Bauder for his continual support and helpful directions in supervising my major research paper. I would also like to thank Dr. Vappu Tyyskä, my second reader, for her consistent guidance throughout the program and completion of this project. 


\section{Table of Contents}

Author's Declaration ................................................................... ii

Abstract ...........................................................................................

Acknowledgements ....................................................................... iv

Chapter 1: Introduction ..................................................................

Chapter 2: Literature Review …………………………………….... 2

Habitus and Cultural Capital .....................................................

Gentrification and Authenticity ................................................ 11

Ethnic Economies/Ethnic Enclaves .......................................... 13

Little India Background ............................................................... 15

Chapter 3: Research Methods .............................................................. 18

Research Design ............................................................... 18

Selection and Recruitment ..................................................... 21

Chapter 4: Findings and Analysis ......................................................... 23

Looks, practices, styles, and tastes .............................................. $\quad 23$

Findings - Restaurant 1 .............................................. 23

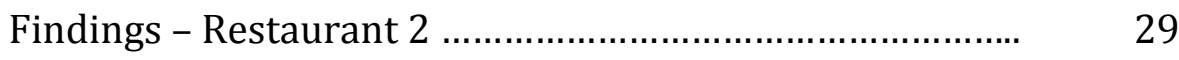

Analysis ................................................................... 33

Ethnic habitus and business success............................................. $\quad 35$

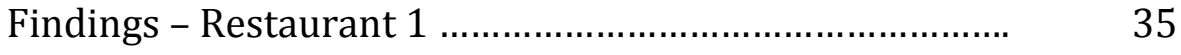

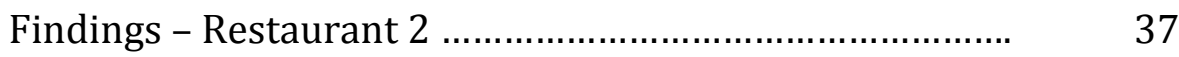

Analysis .................................................................. 39

Changing habitus...................................................................... 40

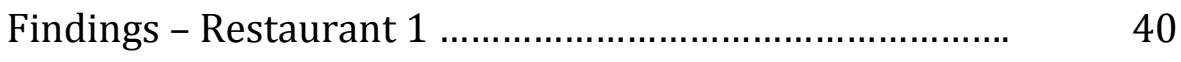

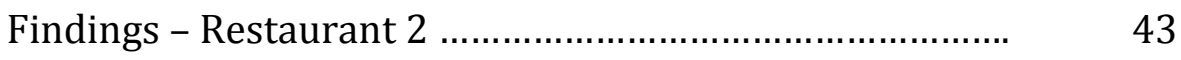

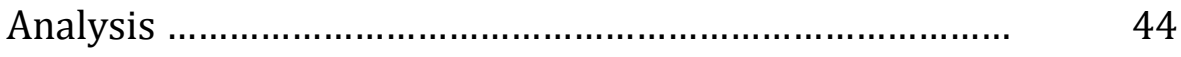

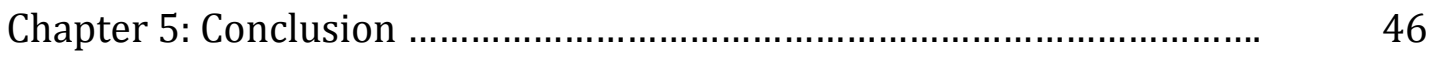




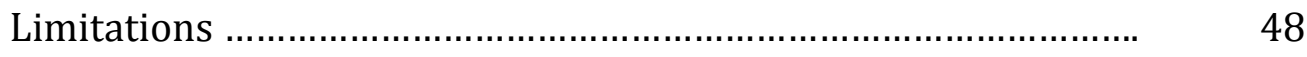

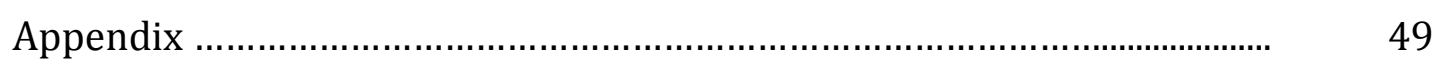

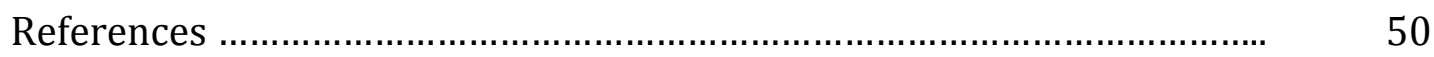




\section{Chapter 1: INTRODUCTION}

Much of the previous research on ethnic businesses focuses on migrants' settlement experience and how self-employed migrants fare in their business ventures (Bagwell, 2007; Bauder, 2005; Ley, 2005; Li, 2001). Gentrification in ethnic economies is a relatively new occurrence may adversely impact the ethnic businesses that once revitalized areas, such as Toronto's Little India. It is important to study how redevelopment of a community impacts migrant entrepreneurs, the approaches and specific tactics that these entrepreneurs are implementing to help them succeed, and the role of business owners' ethnic habitus and cultural capital in running their business. This study investigates two restaurants located in Toronto's Little India, with the first restaurant celebrating an authentic South Asian ethnic background and the second being a non-South Asian business that has recently been introduced to the Little India area. The methodological approach to this research will begin with an observation of two chosen restaurants, one representing an authentic (will be discussed below) business and the other, a non-South Asian store in the area, followed by in-depth semi-structured interviews of each restaurant owner or manager, further supplementing what was found in the observations conducted.

The topic of self-employed migrants has been an important and integral part of the literature on immigration. Incorporating how migrants integrate their unique cultural background and practices in the new country's business areas would be an interesting approach in advocating cultural diversity amongst small businesses and entrepreneurs. This study will explore the differing approaches that migrant South Asian business owners use, and will apply Pierre Bourdieu's theoretical perspective of the habitus in 
business development. Specifically, this paper examines if self-employed migrants incorporate their ethnic habitus and their subsequent practices in running their businesses, or if they strive to attract the population of the surrounding residential area by marketing their business in a way that would attract the non-South Asian population. The focus on the habitus in this research will be further defined in examining the role of each restaurant's respective culture (South Asian and non-South Asian gentrifying community) and how this may have an impact on how owners decide to market and develop their business. The degree of cultural development can differ with each restaurant, based on its overall business approach. Focusing on Bourdieu's concept of habitus as a theoretical perspective, this paper will examine three main research questions: 1) What are the different looks, practices, styles, and tastes prevalent amongst these two restaurants in Little India? 2) Do the styles and tastes projected by the restaurants' ethnic habitus have an impact on how ethnic businesses fare? The ethnic habitus can be measured through the interaction with customers, tastes, and styles. 3) Are entrepreneurs able or unable to modify their business practices, and styles for the purpose of attracting a varied clientele (non-South Asian or South Asian)?

\section{Chapter 2: LITERATURE REVIEW}

In this section, I will review the literature on the habitus, gentrification and authenticity, ethnic enclaves and ethnic economies, and provide some historical background information on the Gerrard India Bazaar and the Business Improvement Area. 


\section{Habitus and Cultural Capital}

This paper will examine the process of gentrification and its impact on ethnic business development in Toronto's Little India, through the theoretical focus of the habitus by Pierre Bourdieu $(1977,1984,1998)$. The habitus is defined as a system of schemes of perception and thought that acts as an organizing principle of behaviour (Bourdieu, 1977, 18). Bourdieu indicates that this theoretical framework is dependent on an individual's class or group membership. Therefore, a specific set of rules of engagement for a particular group defines their subsequent habitus. Following these rules becomes indicative of a person's membership to the group. The statuses of individuals within the group are determined by their ability to play by these rules (Bauder, 2005; Bourdieu, 1977, 1984, 1998). Habitus describes those internalized structures, dispositions, tendencies, habits, and ways of acting, that are both individualistic and yet typical of one's social groups, communities, families, and historical position (Bourdieu, 1990). Bourdieu sees the habitus through a lens that does not essentialize culture where it would be described as a primordial concept that is ingrained. Rather, viewing the build up of culture through people's reality and surroundings, suggests that individuals may face gradual cultural changes as they experience variations of material context. By not essentializing and not limiting culture, individuals can attribute the changes that they experience throughout life to a different viewpoint and understanding of their culture.

This can be seen in "exotic" hybrid ethnic restaurants, as such businesses both celebrate their cultural and historical position but also re-create their habitus in line with the changing nature of their surrounding "field" (social space). 
The idea of culture changing as a result of an individual's surrounding environment is also evaluated by Bonacich (1999) who, similar to Bourdieu, uses class relations and individual dynamics to define ethnic and race relations. This method allows individuals to gain an understanding of their everyday experiences in society, providing them with the ability to use everyday life experiences to slowly change their own reality and their conception of ethnicity and race. Bourdieu views the habitus as a procedure of continuous structuring of one's social space. By combining the space that we are a part of (migration to a new space) and the dispositions of individual taste (authentic taste and the cultural capital that we bring with us to the new country) we can, then, develop our own social space (Oliver \& O'Reilly, 2010). To obtain a better understanding of our surroundings, Bourdieu suggests the recreation of divisions that make-up social space, such as preferences in art, culture, taste, lifestyle, and cuisine. There are some possibilities for the habitus to transform and reinvent itself, especially when an individual encounters an unfamiliar field. Therefore, to successfully integrate into the new country, migrants may experience a change in the habitus they identify with. With the change in gentrification, migrants who do not identify with the habitus of their surrounding social space are expected to adapt their habitus in successfully understanding the habitual rules that have been established for their localized community (Bauder, 2006). Despite being able to change the habitus to incorporate that of the new environment, the habitus is a slowly changing process that tends to be unconscious and long term (Bourdieu 1977).

South Asian focused restaurants that embody a foreign habitus, and a South Asian social field, may not be competitive with a predominantly non-South Asian clientele. However, South Asian (exotic) restaurants may experience more success in attracting 
non-South Asian clientele because they exemplify a social field that caters to the gentrifying neighbourhood, if they formulate a business approach that is in line with the rules and consumer behaviour of the gentrifying population while celebrating their exoticism (ex; playing around with tastes and styles - incorporating both the Western and South Asian habitus' to their business development),. Although such exotic restaurants may still represent a foreign habitus, they are also following the extensive rules set for them in the country of migration and the neighbourhood of gentrifyers that their business is located in. However, the commonality of the habitus within a particular community may help businesses and migrants in the area succeed and feel a sense of comfort. For example, a study of South Asian networks in Vancouver finds that working alongside coethnic coworkers is beneficial for South Asian migrants as they experience a sense of comfort, being able to communicate in Punjabi and develop a unique sense of trust resulting from the similarity of rules (habitus) that they follow (Walton-Roberts \& Hiebert, 1997).

However, in differentiating between the residential population of gentrifying neighbourhoods and migrants, it is important to distinguish that Western and non-South Asian cultures are not monolithic categories. The practices and styles of this community are dependent on the residential context of the chosen area and the subsequent culture of those that are gentrifying the neighbourhood. In the case of Little India, gentrification is seen through the socio-economic and class differences of individuals that move into the community. The wealthy residents that gentrify the area bring with them their own unique tastes and styles that are representative of their habitus. As a result, the stylistic changes in the business area closely resemble the gentrifyers' habitus and style rather 
than the South Asian habitus. By introducing a new style and habitus to the area, nonethnic businesses are established. Nonetheless, non-South Asian residents may be intrigued by the exoticism of the South Asian culture but only to the extent to which these habits are in line with their own taste and styles, not necessarily representing a truly authentic South Asian experience.

Previous research has argued that immigrants develop a habitus that is representative of their country of origin and these ethnically specific rules may not be easily applicable to the defined rules of the new country (Casey, 2001; Bauder, 2005). As a result, this paper strives to argue that the South Asian habitus may not quite match the rules or practices celebrated in Canada by self-employed Canadians or non-South Asian customers in the restaurant business. Being unfamiliar with these set norms and rules, ethnically focused businesses and self-employed migrants may experience difficulties in attracting non-South Asian clientele. As self-employed migrants embrace their own culturally celebrated rules and practices, these may not be familiar to what is understood by the gentrifying population and their respective tastes and styles, creating a sense of reluctance for non-South Asian customers to visit the restaurant. The lack of cultural competence that many self-employed migrants experience may lead to their inability to attract non-South Asian customers. Bourdieu specifies that the rules and the habitus are strategically developed and are beneficial to those who set and obey the rules (Bauder, 2005). Immigrants who do not follow the specified informal rules and subtle expectations of social and cultural engagement, that are set for entrepreneurs in a localized gentrifying area, may not be competitive. Meanwhile, their non-South Asian self-employed counterparts who identify with and may, as a result, effectively observe these informal 
rules, may experience more success in attracting clientele from the area. Accordingly, those who do bring a foreign habitus but follow these rules, may have a chance at being competitive amongst non-South Asian entrepreneurs who have a good grasp on these local norms and expectations, simply because they are following these rules.

This phenomenon is widely examined in the academic literature on self-employed migrants and the role of their cultural background and origin in business development (Bauder, 2006; Ley, 199; Ley, 2003). Bauder (2005) also questions how entrepreneurs' cultural backgrounds may impact the development of their businesses, finding that geographical regions play an important role in the habitual behaviour of self-employed migrants and the way in which they develop their business, while ethnic origin may not play a large role. Therefore, immigrants' country of origin and the new country of residence are both significant factors to consider in assessing business success in a particular area. A study comparing self-employed migrants from Korea, Hong Kong, and Taiwan in Vancouver found that amongst the three groups, Koreans were much more likely to venture outside of the ethnic enclave and have less of a reliance on their transnational relations in developing their business. Nonetheless, Koreans were also much more successful in their business ventures (Ley, 2005). These findings suggest that the act of breaking into the mainstream and straying away from transnational business linkages could have been what led to the success of self-employed Koreans. Based on this study, it can also be argued that placing too much emphasis on one's ethnic origin in developing a business, may adversely impact migrants' integration into the new country. As a result, being involved in transnational business linkages and incorporating one's 
culture may slow down the process of successful social and cultural engagement into the localized business markets (Ley, 2005; Bauder, 2006).

The habitus that is embodied amongst ethnic businesses run by self-employed migrants can be defined through examining migrants' cultural capital. Bourdieu defines the notion of cultural capital through three main categories; embodied, institutionalized, and objectified. The Embodied category predominantly speaks to the rule of the habitus through bodily expressions and speaking as markers of distinction (e.g. taste, presentation, etc). The Institutionalized category discusses the role of formal and informal education on the development of cultural capital, and the objectified cultural capital relates to objects that may be owned or identified by individuals as a representation of their culture (Bourdieu, 1986). Using these three categories, individual cultural capital is identified and attributed in defining the habitus. An interesting term that has been suggested is that of migration-specific cultural capital (Erel, 2010) indicating that as individuals endure the process of migration, the development of cultural capital becomes a fluid process that can go through varying changes as the individual is exposed to other cultures. The idea of changing cultural capital further addresses how migrants' engage in both expressing their cultural capital from the country of origin and the new cultural conventions prevalent in their new home country.

The rules that help define the cultural capital and habitus of a country are determined locally, and in the case of this study, by the gentrifying residential population in Little India. Bauder (2006) discusses the importance of migrants following the rules associated with the surrounding cultural conventions to successfully engage in their new home. Similarly, in the context of ethnic economies, there are rules set in place for effectively 
operating a business, and if migrants are unfamiliar with these rules, they may face difficulties in successfully conducting a business in the area.

Bourdieu (1984) looks at cultural capital as a "treasure chest" in which an individuals language skills, knowledge about customs and lifestyles, and professional qualifications are all placed in a box, and instead of looking for an exact "fit", the migrant engages in a bargaining activity with institutions (greater public or ethnic economy) and people about the value of their own cultural capital in the new country (Bourdieu, 1984). Throughout this process, migrants' culturally specific cultural capital may be undervalued in comparison to what is appreciated by the local clientele in Little India's gentrifying neighbourhood. However, Bourdieu (1984) discusses that migrants have the opportunity to add new skills to their already well-developed cultural capital, indicating that the negotiation between old and newfound skills can benefit individuals with access to cultural resources in two national contexts. Therefore, in discussing cultural capital, there are two processes as indicated by Bourdieu: the importance of creating new forms of capital in the host society, and migrants taking part in creating a sense of validation for their own cultural capital. This could be done by engaging with their own migrant networks and could perhaps be seen as a form of motivation to set up shop in ethnic enclaves and form ethnic economies. However, to thoroughly identify the significance of individual cultural capital and its role in producing recognizable social identities and personalities, it is imperative to examine how each individual defines their respective cultural practices and the meanings behind these actions. Erel (2010) also discusses the issue of privileged access to skilled jobs for those considered as properly part of the nation, excluding migrants. Therefore this can be related to gentrified communities where 
the non-migrant focused businesses may take over a previously designated ethnic economy. As a result, in light of the gentrifying neighbourhood, current ethnic focused businesses must adapt their habitus and cultural capital to develop and market themselves in a way that will attract the non-South Asian public. Similarly to the privileged access to skilled jobs, access to a thriving ethnic business in a gentrifying neighbourhood may prove difficult if migrants do not identify or understand the customs and norms of the neighbourhood.

For the purposes of this paper, the habitus will be identified through an examination of each restaurants looks, practices, and styles that are presented. These factors will serve as indicators of the way in which the habitus is typically defined within each establishment. Similarly, Amdur et al.’s (1992) study on immigrant workers in restaurants in New York City has found that examining the servers and the way in which they present themselves can help provide us with the descriptive information in defining the habitus in the context of these restaurants. "Waiters contribute to the production, circulation, and consumption of symbols" (p.156). The authors further emphasize this point by indicating that a “restaurant's style is both implicitly and explicitly negotiated by waiters and the management" (p. 156). Therefore, the accents, languages spoken, clothes worn, and interactions between the servers can help define the habitus in this particular environment. These descriptive features can be just as helpful as an analysis of a restaurant's menu, prices, and location. As a result, these factors played an important role in providing a better understanding of the habitus and cultural capital presented in the restaurant and the way that it is negotiated to attract clientele. Other studies, such as Alraouf (2010) and his focus on regenerating urban traditions in Bahrain also use similar 
methods of descriptive factors that help define authenticity and the habitus: "Buildings, streets, people, smells, sounds, colours, motions, etc are inherent and inextricable components that make cities what they are and construct their authentic memory" (p. 66). The social spaces of restaurants allow business owners to develop a business approach that is in line with the surrounding area. As the Little India area experiences gentrification, the ethnic businesses in the neighbourhood may have to redefine their businesses as a result.

\section{Gentrification and Authenticity}

For the purposes of this study, it is important to define the concepts of gentrification and authenticity. Gentrification and the idea of 'global urbanism' (King, 2004) focus on the act of developing, preserving, and restoration of an area, resulting in a subsequent change in the demography and overall characteristic of the surrounding residential space (Zukin, 2009). Global urbanism celebrates the move towards aesthetic and residential sameness, eventually leading to a loss of cultural vitality. Hackworth \& Rekers (2005) incorporate economic and cultural capital interests into their definition of gentrification, indicating that an urban landscape is created through reinvestment of the area to meet the needs of a new community with differing tastes and preferences. This is the phenomenon that Little India is currently experiencing, where a once predominantly South Asian business area is slowly transforming into a location that already houses non-South Asian residential properties and some businesses. Therefore, a large non-South Asian population and subsequent businesses targeted for their needs can introduce a specified local habitus that is representative of the cultural customs and norms of this neighbourhood's residential population. As a result of this localized habitus, South Asian 
businesses that embody an authentic approach that differs from the cultural customs of the surrounding area may not attract as many non-South Asian clientele.

Authenticity is understood as the uniqueness in individual cultural origins. In defining the concept of authenticity, Zukin (2009) determines three outlining features. Firstly, in lieu of global urbanism, authenticity can help identify individual cultural development. Secondly, authenticity helps connect the individual in search of an identity, and thirdly, as an environment experiences changes in the physical and social field, the idea of authenticity is viewed as a concern of cultural preservation and displacement in light of these changes. For the purposes of this paper, I will be focusing on the third definition, specifically focusing on the concern that arises from environmental change, and how that impacts business development and the overall ethnic habitus of the business. In trying to incorporate culture and authenticity in a community that is experiencing gentrification, many scholars (e.g. Alraouf, 2010; Cook, 2008; Cwiertka, 2005) believe that the more praise restaurants receive for their authenticity leads to an occurrence of inauthenticity, where practices that were once deemed authentic are modified to meet the needs of the Western culture while they embark in an exotic celebration of a different culture. As a result, the cultural differences that are emphasized by successful ethnic businesses tend to be representative of habitual practices that are defined by the surrounding neighbourhood, where ethnic businesses can obtain a profit by catering to a varied clientele (PottieSherman \& Hiebert, 2015). To obtain a profit in a gentrifying neighbourhood, ethnic businesses may choose to highlight cultural differences that can be understood and appreciated by the surrounding residential and clientele population. 


\section{Ethnic Economies/Ethnic Enclaves}

To thoroughly understand the workings of Little India as a business area, it is important to identify how this area is understood in academic literature. There are two key terms that have been discussed in previous literature that may relate to this ethnically focused business area - the ethnic enclave economy and the ethnic economy. There are specific ways in which these two terms are differentiated based on what they represent. The ethnic enclave economy focuses on two main characteristics - a large number of migrant owned ethnic businesses in which co-ethnics are hired and a location that showcases a collection of specific ethnically focused businesses (Portes, 1981; Light et. Al., 1994). Conversely, the ethnic economy was first defined by Bonacich and Modell (1980) where the concept focuses on migrant business owners and the hiring of co-ethnic employees, only emphasizing the importance of hiring co-ethnics, not necessarily being concerned with the surrounding businesses and their respective ethnicity. The concept of ethnic economies is more broadly focused and can be widely applied to ethnic businesses that may not be located in ethnically clustered business and residential areas, while the rules for an ethnic enclave economy are much more stringent for both employee selection and the location of business (Light et. Al., 1994). When the surrounding businesses and population are not representative of similar ethnicities, the area cannot be fully defined as an ethnic enclave economy. However, despite not having a co-ethnic neighbourhood, research has found that ethnic economies, such as Toronto's Gerrard India Bazaar, have been able to thrive, provided that the economy presents a collaboration of social, economic, and institutional factors that lead to an institutional completeness, a condition that reproduces most of an ethnic community's institutional needs in which a unique 
social environment is created, addressing the needs of the residential population, and considers the differing habitus of the community in presenting itself (Suorineni, 2010).

With gentrification taking place in Little India, businesses that are not co-ethnic are opening, proving difficult to identify with the ethnic enclave economy. In addition, the fact that the residential population does not consist of co-ethnic South Asian individuals, the lack of co-ethnics residing in close proximity may also prove difficult in using the ethnic enclave economy concept. Furthermore, the lack of focus on self-employed migrants under the definition of ethnic enclave economies may not help in thoroughly analyzing the ethnic businesses in Toronto's Little India. Therefore, this paper will focus on using the ethnic economy conceptual way of thought in understanding ethnically focused businesses in Little India.

These two terms have been used to analyze this area, as this business area is unique in the adaptations that it has faced through the process of gentrification. It can be argued that this neighbourhood was once identified under the ethnic enclave economy. However, as more non-South Asian residences and businesses move into the area, the neighbourhood is identified as an ethnic economy where the surrounding residential population and businesses are not of South-Asian descent. With these transformations, there is a subsequent socioeconomic change seen in the residential population. As a result, these individuals bring with them a unique set of cultural norms and values in the styles, tastes, and practices that they prefer. Therefore, the cultural capital and habitus of the neighbourhood slowly becomes more representative of the residential population and their specified needs. The changes in the social field of the neighbourhood are accompanied by a specific habitus and cultural capital that may not be representative of 
what South Asian businesses in the community are familiar with. Consequently, the adaptation to an ethnic economy and a gentrifying neighbourhood presents South-Asian business owners with new customs, practices, and cultural habitus' that are widely celebrated by the non-South Asian clientele.

\section{Little India Background}

Toronto's Little India is located on Gerrard St. East between Greenwood Ave. and Coxwell Ave. This ethnic economy has developed over the years in a unique manner that differs from the typical development of ethnic economies. Unlike most ethnic economies, this area does not have a corresponding local ethnic customer base (Bauder \& Suorineni, 2010; Bauder \& Ritchie, 2011; Zhuang, 2013). Throughout the years, Little India and its corresponding businesses have experienced gentrification. As South Asian migrants gradually move towards a suburban residential settlement area, away from the center of the city, this may have an impact on the ethnic customer base within the Little India ethnic retail facility. As explained by the Dispersed City Hypothesis (Burton, 1963), many South Asian migrants tend to move to the suburbs of the city due to rising real estate costs and exorbitant rent costs found in the core and downtown areas of the city (Bateman, 2014). As this group of migrants collectively moves to the suburbs, new ethnic economies around their respective suburban residential areas are developed, giving them less of a reason to travel to Toronto's Little India, located east of downtown Toronto. Therefore, many academics believe that Toronto's Little India is slowly losing its South Asian identity as potential clientele living in the suburbs have access to similar ethnic businesses conveniently located near their homes, leading to the closure of unsuccessful ethnic businesses in Little India (Bateman, 2014; Kaminer, 2014; Paez, 2014). 
The Gerrard India Bazaar Business Improvement Area (GIB BIA, 2015) was first approved in July 1982 (Bauder \& Suorineni, 2010). This commercial strip's transformation to South Asian focused businesses first began in 1972 when an immigrant from India, Gian Naaz, opened up the Naaz theatre, later owning the property in 1974, showing films in all kinds of different South Asian dialects attracted the migrant South Asian community to Gerrard Street. In doing so, many Pakistani, Indian, Sri Lankan, and Bangladeshi businesses began opening up in the area due to the large South Asian population that it attracted. This area had slowly obtained a distinct South Asian identity that differed from the surrounding residential population. The Gerrard India Bazaar became a tourist attraction known for housing the first South Asian focused theatre in North America, with the ethnic businesses consistently attracting visitors from Detroit, Chicago, New York, Buffalo, and Montreal (Hudson, 2015).

However, as mentioned by the dispersed city hypothesis, new ethnic enclave economies were gradually being established in the suburbs. With a high concentration of the South Asian population choosing suburban residences, many of the ethnic businesses in Toronto's Little India struggled to attract customers (Bauder \& Suorineni, 2010). The mismatch between the retail and residential identities of the area around Little India became more prominent. Because of the lack of clientele with similar cultural identities in close proximity, it is interesting to examine the business development approaches that are implemented by self-employed migrants to help their businesses thrive. Previous research has suggested that many ethnic businesses will take on 'mainstream' approaches to business development, specifically in the planning and design of their business approach, in hopes of attracting customers that may not share their unique ethnic identity 
(Kumar \& Martin, 2004; Zhuang, 2013). Implementing these approaches involves the understanding of the cultural capital and habitus that has been established by the surrounding population, and in doing so, businesses can present themselves in a way that is well understood by the surrounding clientele.

Based on neighbourhood demographics from Census tracks in 2011,65\% of the Greenwood-Coxwell area residents indicated that their mother tongue was English, while the top non-official mother tongue language was Cantonese. Of the overall population of this area, $63 \%$ are born in Canada and $42 \%$ of the population were defined as members of a visible minority group, with Chinese residents representing the top visible minority group (NHS Census Data, 2011). This data further reflects the disparity between the South Asian ethnic retail identity and the general residential population's identity in the surrounding area, as there is a high representation of Canadian-born non-immigrants with English as their mother tongue. Statisticians have indicated that in comparison to the number of immigrants residing in Toronto overall, this particular area has a smaller number of migrant residents (Bateman, 2014), and there are comparatively few members of the South Asian community residing in the area. This sentiment is mainly shared by the business owners, as many migrant entrepreneurs have indicated that over the years, the state of their businesses and attraction of clientele have severely declined, with some questioning their own tactics. For example, a business owner interviewed by a journalist speaks of the changes that the gentrifying neighbourhood has experienced and suggests that 'maybe we didn't take care of things properly' (Paez, 2014). This quote indicates that the ethnic business owners in the area are aware of the cultural changes in the 
neighbourhood and perhaps they should have done something to maintain the South Asian culture that was once widely celebrated in the area.

Vacant lots and empty storefronts are prevalent in this area as new non-South Asian focused stores, coffee shops and art galleries are beginning to appear and take over these vacant lots in order to better cater to the widely celebrated class and cultural characteristics that are being introduced into this gentrifying neighbourhood. The area is experiencing severe planning and developmental changes that may or may not have a subsequent impact on the general ethnic economy that was once built amongst the South Asian community. Nonetheless, despite the changes that are taking place, there is also a great degree of stability amongst families who have held onto their ethnic businesses for 40 or 50 years; a motivating factor is that many of these business owners are also the owners of these properties (Hudson, 2015).

\section{Chapter 3: RESEARCH METHODS}

\section{Research Design}

This study examined the differing approaches that South Asian business owners use, and observed the role of the habitus in the development of ethnic businesses. Through several walking tours and a comparison of other restaurants that matched the criteria. Two restaurants were chosen with the consent of respective store owners, each representing a main category of analysis based on the specific approach of business development in regards to ethnic authenticity.

The methodology was took an ethnographic approach in consisting of two parts beginning with a naturalistic observation of two chosen restaurants within the Little India 
area, following up with two semi-structured interviews. This methodological approach was also used in the study of migrant workers in New York City restaurants by Amdur et. al (1992). In the study by Amdur et. al (1992), four restaurants were chosen based on observation, and subsequent interview questions were developed in supplementing the findings that were observed. Zhuang (2013) also makes use of participant observation during field visits to enhance the information gathered on multicultural planning in ethnic business areas, such as Toronto’s Little India. Pottie-Sherman \& Hiebert (2015) use a similar ethnographic qualitative method of observation and follow-up interviews in defining cultural authenticity in Richmond, Vancouver's Night Market. Therefore, these combinations of methods have been used successfully in the past, specifically in literature on ethnic businesses.

The study selected a sample of two restaurants based on the criteria of an authentic restaurant that truly embodies the South Asian ethnicity in their business development, and a non-South Asian restaurant located within the area. The naturalistic observation of each restaurant began by the researcher attending each restaurant two times a week, once during the weekday in the daytime hours and once during the weekend in the evening hours to observe presentation of food and decor, menu selection, clientele and the interaction between servers, owners, and the general public around the restaurant area. Each of the two restaurants were visited on two separate occasions within the span of two weeks, and each visit was approximately an hour long. I was able to thoroughly observe and take notes on the surroundings and the unique habitus that may be presented within each restaurant with a differing criteria.

In examining each restaurant, the research assessed what has been operationalized as 
the habitus. Detailed notes were taken about the restaurant décor, presentation, clientele, servers, other staff members, aesthetics (food presentation), the items being served, the structure of the menu, business hours, languages spoken, smells, tastes, analysis of marketing material to help attract customers (websites, delivery systems, advertisements), and if an ethnic cultural approach has been incorporated or one that appeals to a nonSouth Asian clientele. In discussing how individuals extract new information about others, Bourdieu (1984) considers the importance of the habitus, as defined through the tasks that people take on, the way that they dress, and their behaviour in a specific environment. Therefore, the chosen method of defining the habitus that is performed in each restaurant is well justified by how Bourdieu would define and understand the concept. Based on observations, the research examined how the concept of habitus is performed within each business.

In addition, I conducted interviews with the business owners or managers. The interviews took place outside of the two visits outlined for naturalistic observation of each restaurant, and a time was found that was most convenient for the owners or managers to be interviewed. One semi-structured interview, lasting as long as 60 minutes, took place with restaurant owners or managers of each establishment. Interview questions were open-ended, further discussing what was observed and the reasoning behind specific approaches of business development. By taking an ethnographic approach, the research has allowed for a broadened scope of focus as the two interviews were conducted to provide more information on the strategies and business development techniques examined through the observations that were made. In addition, the research is framed as a case study so that it can be applied to other communities, asking critical questions, 
while the research derives sufficient findings and engages in subsequent analysis of the data. The interview guide, indicating the research and interview questions, is included in the appendix.

\section{Selection and Recruitment}

Two restaurants were chosen for the naturalistic observation and subsequent interviews were conducted with restaurant owners or managers. The two restaurants were chosen based on my two categories of analysis of authenticity and non-South Asian restaurants. A restaurant was chosen based on each of these categories and subsequent interview subjects, owners or managers of each restaurant, were selected. When examining the potential impact that owners and managers' South Asian culture may have in their business development, it is important that the authentic restaurant that is chosen has a representing manager or owner of South Asian descent, to thoroughly speak of the role that their culture plays in their ethnic business. However, for the purposes of this study, it is not required for the non-South Asian restaurant to be specifically interviewed by South Asian managers or owners to differentiate between the cultural habitus of nonSouth Asian and South Asian business owners.

Restaurants that are not located in Toronto's Little India were not included, as they did not represent the focus of gentrification within the Little India business area. In addition, restaurants that did not fall under the two aforementioned categories were not included for the purposes of this study, as they would not follow the comparative guidelines of the study.

The interviews were audiotaped to thoroughly analyze the answers provided to each question posed. Names of restaurants, interviewees, and all other identifying information 
were not used. Pseudonyms were assigned to all participants and the restaurants used in the sampling. Given the small number of restaurants that were recruited, one South Asian focused and one non-South Asian, it may have been difficult to ensure confidentiality of the participants. However, the location of study was be extended beyond the Gerrard India Bazaar Business Improvement Area (GIB BIA) to include restaurants along Gerrard Street East from Prust Avenue to Gainsborough Street, to capture a significant number (>10) of different South Asian and non-South Asian restaurants added to the potential sample.

The two appropriate restaurants were chosen through an examination of the restaurants in the surrounding area and existing research done on which businesses would best match the selection criteria (ex. Bauder \& Suorineni, 2010). I used the two categories as my main recruitment criteria in selecting the restaurants. The authentic restaurant was a business that represents the South Asian culture by embracing a "South Asian" ethnic habitus, and the second restaurant was a non-South Asian business located within the Little India ethnic economy. Once each restaurant was selected, I visited each restaurant and their respective owner or manager and provided a recruitment script and consent form outlining the details of the study.

Recruitment was conducted through consultations with South Asian community members and walking tours of the area to become better acquainted with the businesses and finding restaurants that would match the chosen sampling criteria. I approached two authentic and two non-South Asian restaurant owners before I chose the restaurants to be observed analyzed. Once the restaurants were selected, I arranged a meeting with the storeowners to explain the study and go over the details presented in the consent form. 
After consent was received, I began my observation of each restaurant and arranged for a follow-up date to conduct the interview.

\section{Chapter 4: FINDINGS \& ANALYSIS}

This paper focuses on three main research questions in examining the role of the habitus as seen in small businesses located in Toronto's Little India. In examining varying restaurants that have established themselves in this gentrifying ethnic economy, where structural and social redevelopment is taking place, this research focuses on 1) questioning and differentiating between the looks, practices, styles, and tastes that are

prevalent amongst these carefully selected restaurants; 2) the role of ethnic habitus and the impact it may or may not have on how ethnic businesses fare in the gentrifying neighborhood of Toronto's Little India; and 3) whether entrepreneurs are able or unable to modify their business practices and styles, in effect, making changes to their habitus. The following sections will present the findings and analysis as seen through the three main research questions initially posed. Each sub-section is representative of a research question and will first present the findings from restaurant 1 followed by restaurant 2 for the observation and interviews conducted, followed by an analysis of the methods for each research question.

\section{A) - Looks, practices, styles, and tastes}

\section{RESTAURANT 1}

Restaurant 1 is a small authentically Indian restaurant, which has been an integral part of this ethnic economy. Based on what was observed and later confirmed by the interviewee, the close resemblance, not only in taste but also in design, that this 
restaurant has to similar businesses back home in India, has made it a authentic experience for South Asian clientele. The authenticity of this restaurant is determined in the presentation of décor and, most importantly, the emphasis placed on representing the original taste of authentic Indian cuisines in food preparation and presentation. To help maintain the authentic taste, the restaurant owners and chefs have taken a similar approach in food preparation to their home towns, where cooks are often using their hands rather than relying on machines in preparing the food.

Further looking into the menu in analyzing the authenticity of the items presented, the focus has been placed on obtaining an authentic taste, and so the menu is consistently changed to achieve that taste. When asked about the structure and motivation behind the items on the menu, the owner mentioned that: "They were very eager on obtaining the taste of certain things, for example the Chana Masala (chick peas), that recipe was probably changed about 20 times over". Therefore, the interviewee indicates the importance of ensuring that the items on the menu are representative of the authentic dishes found in India, and so they often engage in changing their methods of food preparation to obtain that authentic taste. The restaurant owner speaks of the attraction that the restaurant gains from South Asian migrants longing for the food that they had left behind back home, indicating that their number one selling items are authentic Indian dishes. Many clienteles often indicate that "now I don't miss Delhi, why? Because, I am getting the same Chana”. Therefore, while many of the still-running authentic restaurants in the area try to slightly incorporate the South Asian culture and ethnic taste into the varied culture that is developed by the gentrifying neighbourhood, this authentic 
restaurant primarily preserves the feel and experience of visiting an authentic restaurant back in India.

As an example, Butter Chicken is a specialty Indian dish that is widely known amongst the Western population as an exotic celebration of the Indian culture. However, in many mainstream Indian restaurants, this dish has slowly lost its authentic taste and flavour to meet the taste needs of the Westernized population, perhaps reducing the number of spices that would add flavour to the meal. This dish is used as a point of differentiating the authentic taste found at this restaurant in comparison to less authentic (exotic) restaurants that also sell this dish. In India, this dish is most often served with the chicken bone in and never includes white meat. The interviewee provides a description of this dish, indicating that it is "very uncommon to find boneless chicken, let alone white meat, let's not even talk about white meat, nobody in India wants to eat that kind of stuff, right? It's too healthy”. To enhance the flavour, authentic Indian restaurants believe in replicating this particular method of preparation.

Nonetheless, despite holding onto an authentic approach in maintaining the taste of the original cultural dishes, Restaurant 1 strives to cater to the non-South Asian clientele that may not necessarily enjoy the authentic approach in preparing these dishes, perhaps a healthier option with white and boneless meat, this is gathered when the interviewee mentions that "We don't believe in boneless, I mean we do it because we want to cater to clientele, we do have it on the menu. But our number one seller will still be bone in, that's where the flavour is". This authentic restaurant places a high regard on maintaining the traditional flavour of their Indian dishes, all the while, being mindful of their surrounding clientele and offering an alternative that would cater to the clientele that are 
unfamiliar with the authenticity of these dishes. Restaurant 1 maintains its authenticity, similar to restaurants in India, by also not using sugar in the sauce for this dish. Other Indian restaurants may prepare their butter chicken by adding sugar to reduce the spicy taste of the traditional dish, accommodating the non-South Asian palate.

The inspiration for the structure of the menu is that the owners are their own clientele, ensuring that their food is up to standards that they themselves would appreciate and enjoy. All in all, this restaurant strives to maintain their authentic approach and it is thoroughly reflected in their choices on the menu. They have taken their traditional customs and practices from their respective home towns in India and incorporated this approach to their overall presentation of food to the community. The interviewee mentions that "We stay away from the non-authenticness, we stuck with 'you leave India and we have two places we want to represent, which is Amritsar and New Delhi',". Both these locations are cities that the owners and restaurant workers have ties to, allowing for a more authentic and rooted cultural restaurant experience.

In decorating the restaurant, similar to the structure and presentation of the menu, there is a general emphasis placed on quality of food and service over the overall presentation and décor of the business. As a result, in trying to resemble Indian restaurants in India with minimal decoration and simplistic design, the restaurant owner indicates that this restaurant has taken on more of a traditional Indian diner approach where simplicity is key. There is not a significant amount of effort placed on the overall décor, quite similar to what would be found in India. This has become their overall focus on not only recreating an authentic taste, but also an authentic physical presentation, one that reminds the South Asian community of their hometowns. 
As the area faces demographic changes in both the surrounding population and businesses, it is important to consider their respective looks, practices, styles, and tastes, to obtain an understanding of how authentic South Asian business owners perceive these changes in businesses. The main issue that was mentioned by the restaurant owner was that of the vacant lots located within Little India. It sends a negative message to the clientele; therefore filling these lots would help everyone in the business area because it would bring in a higher level of exposure to Little India and all the businesses in the area. Regarding the gentrification and the surrounding residents, the owner indicates that there have been some changes, as more young professionals are occupying the residential community and South Asians are moving out, opting for suburban areas such as Brampton, Mississauga, and Scarborough. Therefore, with these changes, in order for businesses to thrive, the owner considers that they, too, should make some changes to adapt to these changes in clientele (similar to what is argued by Bourdieu's habitus).

“We haven't had delivery in ever since we opened, now all of a sudden last year we started delivering, it was a big change to my in-laws who were nonbelievers to that and it was simple - the community is changing, so we have to change with the community. Not necessarily that we're changing the menu to accommodate for these communities, but we're just trying to evolve with the changes that the market requires.

The notion of convenience was a motivating factor for this authentic business to make small changes in trying to attract a diverse clientele. In effect, they deviated from their comfort zone and the habitual behaviour that they have developed over the years in order to expand their business and stay alive in a changing market and clientele base. Although 
the process of changing the habitus may seem counter to the authentic approach, this restaurant has not made changes to the taste, but to the way in which they market and present themselves, hoping to attract a different clientele and inform them of the authentic and exotic South Asian tastes. However, it is interesting to note that as generations of migrants adjust to their environment, they have a better understanding of this changing behaviour. The interviewee supports this by mentioning that implementing new initiatives, such as delivery, was a foreign concept to the original owners who had established the business many years ago upon migration to Canada. Nonetheless, being influenced by individuals who understand the importance of a changing habitus seems quite imperative for authentic restaurants to ensure that they are competitive amongst the changing clientele and changing cultural habitus in the surrounding area.

As a result, the neighbourhood surrounding Little India is of great importance, and the subsequent changes that occur with the residential population are an important factor to consider when examining the state of the businesses in the ethnic economy. This particular area is located directly east of the heart of the city of Toronto, and as a result, being quite far from the center of the city, it is not deemed a location that attracts many everyday passers-by or traffic. Therefore, the surrounding residential populations are the main clienteles that may frequent the businesses in this particular area.

The neighbourhood's gentrification and population changes directly impact the ethnic and non-ethnic businesses in the area. There is a general trend towards non-South Asian businesses opening in the area, however, it does not seem problematic because the consensus, as mentioned by this particular authentic Indian restaurant owner and many Business Improvement Area (BIA) members, is that these new non-South Asian 
businesses are bringing in clientele that would not otherwise be attracted to this area and its emerging businesses. This is further reinforced by the interviewee mentioning, "I think it's great. Any business that opens up here, brings their own clientele, every clientele that comes to the bazaar is bringing exposure to me”.

This co-existence is prevalent in this particular community, not only among the south Asian and non-South Asian restaurants but also between the South Asian restaurants themselves. Upon observation, it was clear that the clientele of the community often frequent each business for its specific specialty, whether it is vegetarian, non-vegetarian, sweets, or drinks. Successful restaurants have been able to develop a niche for themselves, one that helps them stand out and co-exist. This owner reflects on the importance of co-existing with one another and accepting each other's unique habitus by speaking of their competitors in the area and the other non-South Asian businesses in the area and how their businesses allow for an increased exposure for business 1 .

\section{RESTAURANT 2}

In the following section, a non-South Asian restaurant, Restaurant 2, will be analyzed through defining the practices and styles that would make up the habitus. This analysis will provide a medium for comparison in differentiating between the authentic and nonSouth Asian restaurants and the habitus of each.

This unique non-South Asian restaurant had initially developed its business in the area to attract the residents that are gentrifying the neighbourhood, who identify with a high socioeconomic status and a differing cultural capital and habitus from that of the South Asian business owners and residents in the community. Restaurant 2 strives to target this 
community's needs by focusing on natural and locally raised foods. The emphasis on providing natural food items is an example of the taste and style that is representative of this gentrifying community, and this focus widely differs from the practices and tastes celebrated by the South Asian culture. This may be seen as a difference in class, where purchasing natural food items are significantly more expensive than mass produced items.

Establishing this business in the Little India area introduced a different kind of restaurant that the area had not necessarily been exposed to. Consequently, the restaurant presented a diverse look, practice, and taste in relation to the surrounding South Asian focused restaurants. Therefore, it established a habitus that may not previously have been as prevalent amongst the other restaurants in the area.

In assessing the menu and comparing the selection of food items offered at this restaurant, through both the observation and the interview, I found that the inspiration behind the menu is based on familial ties and traditions that were prevalent amongst the owner's family and their own specific customs. The business and, subsequently, the menu, were designed with the motivation of resembling what was most valued within their family culture. As a result, the owner displayed values that were taught to them as a child - those of a health conscious, local, and natural approach to food and food preparation. In designing the menu, the owner emphasizes the importance of realizing that, similar to restaurant 1 , the motivation was found within themself and that they are their own customer, being inspired to feed clientele food and beverages that the owner felt comfortable eating. 
Much of the focus behind establishing the restaurant and the menu was due to the family cultural beliefs and values that were ingrained. This is also prevalent in examining the restaurant décor and the symbolism behind the presentation of the restaurant. There is a definite purpose in the way that the restaurant is decorated. There is a rustic but modern presentation with a homey feeling that is representative of a traditional rural angloCanadian style. The restaurant design places emphasis on catering to their targeted clientele of the gentrifying residential community; as a result, the furniture and supportive decorative pieces are carefully selected with the clientele's needs in mind. The owner had a specific design that would fit their own personal needs. Believing themself as a representative of the clientele, the restaurant was designed in that specific way. "You have to know your customer, you really have to know your customer. That's what I've learned." The idea that business owners must truly understand their customers is a belief that was addressed by both interviewees, not only as an inspiration for décor but also in the overall development of the business. The concept of changing to meet customer needs seems to be an important thing to consider, especially in a gentrifying ethnic economy, where the customer base is constantly changing and successful businesses must address the needs of the changing population.

This restaurant may have once been an outlier in a community known for its South Asian focused business area. When questioning how the owner felt about the surrounding South Asian focused businesses and if they impacted the success of restaurant 2, the owner mentions that it does not quite effect how this business is developed, perhaps because of a great distinction between the restaurant and to whom they cater versus all of the South Asian focused restaurants in the area. "And this is the thing, a new shop, just 
because it's new doesn't mean it's going to be good and just because it's ethnic doesn't mean it's going to be good. It's about design, it's about knowing your customer and that's why certain shops survive and some pass away. You have to be able to stay focused on what your customer wants - your customers changed, you better change. Otherwise, you're dead in the water". Once again, the notion of being a flexible business that can evolve and develop as per the respective surrounding community and potential clientele is brought up. This business owner believes that a successful business is not a stagnant business; it is one that is always changing to meet the needs of its customers.

Although Little India is going through gentrification and some extreme population changes, it is still very important to attract other clientele besides the surrounding residential population visiting the area on their way home or out of convenience. The interviewee speaks about the residential population by indicating that "I think population density is important in our neighbourhood because it's mainly people who live in the neighbourhood are coming to us". There should be a motivation for individuals to want to come to this area and a unique idea mentioned by this business owner was that of popup shops. This is a practice that is well developed in the ethnic economy of Greektown on the Danforth where small temporary businesses use vacant lots for a short period of time to attract a specific clientele to the area (DECA - Danforth East Community Association, 2015). This can be used as a potential idea to help enhance the business advancement in the area and help attract more people into Little India. This is important to note because this approach introduces new cultural habitus that the community may not have been exposed to and as a result, can bring in clientele that identify with this new taste and 
approach, while increasing community members' awareness of variant cultures and business practices.

When asked about the changes that restaurant 2 has observed in the neighbourhood since developing their business, the owner makes note of the new non-South Asian focused businesses that have been opening up in the area. According to the owner, there is a wider variety of stores, deviating from the predominantly South Asian centered businesses. When asked about the kinds of changes the restaurant owner would like to see happen in the area, the interviewee mentions a cleaner neighbourhood with increased efforts of beautification to help further attract others into the neighbourhood. In addition, the annual Festival of South Asia, organized by the Gerrard India Bazaar BIA was mentioned. As a non-South Asian business in the area, this restaurant does not seem to attract many customers during this event celebrating the culture of South Asia. The owner feels that the festival, in and of itself, should be improved to help attract more people to both restaurant 2 and the surrounding non-South Asian businesses. Nonetheless, perhaps the attendees do not feel as closely connected or inclined to visit a non-South Asian establishment during a festival targeted for the South Asian community. As a result, there is a mismatch between the cultures that is especially present when such cultural festivals take place, thoroughly differentiating between the South Asian and non-South Asian restaurants in the area because of their particular cultural habitus.

\section{ANALYSIS}

The following section will analyze both Restaurant 1 and Restaurant 2 and the practices and styles that represent each of their habitus. To help establish the difference 
between ethnic habitus prevalent amongst this business area, as defined by Bourdieu (1977, 1984, 1998), it is important to examine the looks, practices, styles, and tastes that are developed in each of the businesses. Considering the authentic and non-South Asian restaurants, it was clear that both take a traditional approach on relying on their familial and cultural backgrounds in designing the menu. Both take personal values into consideration when thinking about their clientele - taking an approach where they believe that they are their own clientele and that they must service their customers in a way that they would want to be serviced themselves. However, despite both relying on familial traditional values and beliefs, the difference in culture is clear when examining the differentiation between the values of each respective restaurant and the way in which they have presented themselves in designing their menu.

The authentic restaurant strives to maintain their authentic taste, one that is traditionally valued by the Indian community, placing an important emphasis on taste. As a result, the authentic restaurant may not be as health conscious in preparation of their dishes (white meat vs. non) because that is what the Indian community would appreciate, dishes that are flavourful and prepared in a similar manner that was done back home. Conversely, the non-South Asian restaurant is predominantly motivated by natural and healthy food and drink options, thoroughly resembling the culture and traditions that were widely both celebrated in the owner's family and by the tastes and practices of the gentrifying residential neighbourhood. This differentiation presents a very interesting dichotomy between the celebrated cultures of each restaurant, indicating that the organizing principles that define their respective behaviours and the kinds of dishes that they offer would attract a specific type of clientele. As mentioned by the authentic 
restaurant, there is a general understanding of the differences between the ethnic habitus of South Asian in comparison to the surrounding non-South Asian residential population and they do strive to cater to these variances. Nonetheless, as mentioned by the interviewee of restaurant 1 , the number one selling items on the authentic restaurants menu are those that resemble the taste, style, and presentation found in similar restaurants in India, developing a truly authentic ethnic habitus.

The restaurant décor and presentation for both restaurants are similarly inspired by their respective cultural backgrounds, trying to replicate a specific design of their past. The non-South Asian restaurant places emphasis on presentation, while that is not the case in the authentic restaurant. This becomes a differentiation between their ethnic habitus of each. The notion of decoration and presentation is not necessarily the focus in the type of restaurant that this authentic establishment is trying to resemble, as was the case in India. While the minimalism is symbolic for the authentic restaurant, the emphasis on decoration is also symbolic for the non-South Asian restaurant. Similar to the motivation behind the items on the menu, both restaurants are generally driven by their respective cultural capital. These inspirations are especially seen in the way that the restaurants present themselves to the greater community, establishing their own unique habitus and environment to be identified by.

\section{B) - Ethnic habitus and business success}

\section{RESTAURANT 1}

The ethnic habitus is an important distinction between South Asian and non-South Asian restaurants in this area. For the purposes of this paper, it is important to consider 
the role impact of the business owners' respective ethnic habitus on how ethnic businesses fare. To assess the reasoning behind the chosen location, despite the gentrification taking place in the area, the interviewee was asked to elaborate on the choice behind the location of restaurant 1 in Little India. When the restaurant first opened in this location, the motivation was mainly that of comfort because of the co-ethnic surrounding businesses, providing South Asian self-employed migrants with a cultural community where they felt most comfortable establishing their business. The owners of restaurant 1 have created a rapport with their client base, which has motivated them to continue running their business in this area. People know about this restaurant and the business has established that rapport, however, as a traditionally authentic restaurant, they must make changes in order to cater to the non-South Asian population. That is especially present in the way that this authentic restaurant has been able to develop itself. The interviewee speaks of a time that the business was stagnant in attracting clientele, by mentioning "We were on a plateau - he [business owner] wanted to go into retirement, until I said let's see where we can go with this and we started inclining again about 3 years ago".

As a result of changes made to effectively market the restaurant to cater to both South Asian and non-South Asian clientele, the business was revitalized and became a busy and well-working restaurant once again. To maintain the same level of customer attraction that they once had, there is a particular focus on quality instead of presentation, as mentioned by the owner that "it's all about coming home, people come here, and we know them". Although it is understood that changes to the business approach are 
imperative to the success of the business, they have not lost focus of their overall purpose in providing a truly authentic experience.

Success is a subjective notion, in the case of this authentic restaurant; the owners have chosen to attribute economic success to the relationships and rapport that they have made with the clientele. As an authentic restaurant, there is a focus on both maintaining a sentimental value for South Asian clientele, while striving to attract and inform the nonSouth Asian population of the unique South Asian culture and taste. As a result, restaurant 1's ethnic habitus is motivated by the owner's idea of success, that of creating a loyal and satisfied clientele base. In doing so, they have maintained the authentic taste and style of their dishes, while making slight changes to the way that they present and market themselves, attracting clientele that may be unfamiliar with the authenticity of the items on the menu.

\section{RESTAURANT 2}

In considering the Little India area and attributing it to a South Asian ethnic habitus, the change in population can lead to slow changes seen amongst the prevalent habitus in the area. For this non-South Asian restaurant, the motivation behind choosing this particular location in the midst of Little India was to cater to a large part of the non-South Asian neighbourhood that were looking for a restaurant where they can bring their family members, spend time, and enjoy the food and beverages that the non-South Asian gentrifying community would prefer. Therefore, because there is a specific client base and a need for this type of an establishment, the opening of this business was well accepted by the community and provided the owner with further motivation to continue 
running this business in the area. The restaurant is doing well in this particular area and the owner's focus is to maintain and grow the business: "We've been well received and we've been successful and hopefully it'll grow with time”. The residential population is motivated by their own particular taste and styles. These motivations become representative of the rules that make up the gentrifying population's cultural habitus in developing businesses that would attract the surrounding non-South Asian population. These businesses would be comprised of restaurants that differ from the authenticity that is displayed within the South Asian focused businesses and the cultural habitus that they would embody. The inclusion of businesses that cater to the practices, styles, and tastes that are in line with the neighbourhood's habitus are mentioned as the owner indicates: "I know there's going to be a pizzeria going in, maybe a brewery down there, but maybe in the next year and that will hopefully bring in more business too". There is a general trend towards businesses opening up in the area that would not necessarily embody a South Asian cultural habitus and it is interesting to note that this business owner focused their analysis on this point. It could be argued that as more businesses are opened up in this neighbourhood that share both the habitus, that she has developed for her business and the specific group of clientele, there may be a diverse set of customers attracted to the area, as a whole.

It is important to differentiate between the ways that the restaurant owners define success, helping us examine how the habitus is defined by the owners and expressed in the way that they develop their business. Restaurant 2 business defined success as wanting and enjoying the work that you do, all the while catering to the general public. In addition, making sure that your supporting team and staff members are also enjoying 
what they do. In line with this definition, the owner responded to questions believing that they are on the right track to achieving their definition of success and developing their business with their own unique habitus in mind - one that may vastly differ from that of the surrounding South Asian focused businesses in the area.

\section{ANALYSIS}

Specifically looking into individual ethnic habitus and the role that this may have on the development of ethnic businesses, the authentic south Asian restaurant indicates the importance of comfort in being in close proximity to co-ethnics. They rely on the importance of a community that understands their cultural habits and were able to converse with each other in their own language, despite living in another country. Conversely, the motivation to establish a non-South Asian business in this area was to cater to the largely non-South Asian residential population. In doing so, an entrepreneur that identified with the non-South Asian group members and also understood the group's rules of engagement, was motivated to develop a business that would cater to the needs of this group of people in the area. As a result, both restaurants indirectly addressed their respective cultural habitus' as motivation to establish, and continue running, their businesses in this particular business area.

Although there is a large non-South Asian residential population in the area, when restaurant 1 was asked about success and how, as an authentic restaurant, they would define this notion, the interviewee mentioned the importance of establishing a business that caters to the needs of their clients (South Asian and non-South Asian). Bourdieu introduced the habitus as a perspective that is not essentialized, in which there is not an 
ingrained form of culture but a concept of culture that may face changes throughout time. This authentic restaurant has been capable of achieving success within their business, because of their dedication to providing an authentic experience for the customer, one that would reiterate their ethnic habitus, invoke a sentimental value to each customer's visit, but is also mindful of the changing population and customer base in its surrounding location. Similarly, the non-South Asian restaurant speaks of success with their clientele in mind, ensuring that they sufficiently serve the needs of the customer whilst creating a community for the customer to be a part of and identify with.

Although both restaurants predominantly represent a different cultural habitus in the way that they have developed their restaurant, it is interesting to note the overlap in their definition of success and their approach in striving to create a community and subsequently catering to the respective needs of their surrounding.

\section{C) - Changing habitus}

\section{RESTAURANT 1}

The ethnic habitus can be seen as a unique defining factor of an ethnic business, creating an identity that may differ from non-South Asian focused businesses in the area. Nonetheless, to attract the non-South Asian surrounding population, it is important to specifically question if entrepreneurs are able or unable to modify their business practices, styles, and approaches. In the authentic South Asian restaurant's case, they have explored new marketing and food preferences that were never really an option and did not fall in line with their initial cultural habitus, that of the authentic approach that they once felt comfortable with. Nonetheless, through new systems such as providing 
delivery and an online presence, they are being exposed to new clientele that they would not have, had they not changed their approaches to deviate from their particular cultural habitus to match that of clientele that may not necessarily share their perspectives. The interviewee speaks of the effective marketing changes, mentioning "Online presence, you've gotta keep up with the times". However, because restaurant 1 is an authentic South Asian restaurant, they must be wary of ways that they make changes, because too much change may adversely impact the clientele that enjoy the authentic taste and presence that is celebrated in this restaurant. Therefore, it's a game of balance, learning the appropriate degree of change that is necessary to help attract all kinds of clientele, without losing their original sense of authenticity and unique cultural habitus.

With the changes taking place in the neighbourhood and the subsequent population transformations, it becomes imperative to question if business owners have felt the need to make changes to their business approach in targeting a specific clientele and addressing the population of residents moving into the surrounding area. For this surviving authentic restaurant, this has become a frequent practice as the clientele and the surrounding residential population changes over time and presents new cultures to the area that may not be as familiar with the South Asian culture. Therefore, representing an authentically focused establishment, the business owner believes that rather than completely changing the well-developed cultural habitus and the taste of the food, the restaurant must be presented in a way that attracts clientele to learn about the South Asian culture and try something that they may have never been exposed to. The authentic business owner comprehends the importance of making the appropriate changes to help attract the non-South Asian residential population by indicating that "Yes, for sure. We 
wanna target the new clientele moving/working in the area, who have not experienced this". In specifically discussing the changes that have affected overall business development, the owner indicated that many of the modifications can be attributed to the changes that the bazaar, as a whole, has made, such as beautification initiatives to attract more people to the area, having an impact on the number of non-South Asian customers that now frequent authentic restaurants in the area.

Taking several walking tours of the Little India area during varying times such as a busy weekend evening or a weekday, it was observed that many of the authentic restaurants were often completely empty, with business owners or workers regularly standing outside of the store trying to attract customers. The business hours of South Asian and non-South Asian restaurants are also important to consider in understanding both cultural differences and the reasoning behind some of the empty restaurants. The South Asian businesses mostly operate for late lunch and dinner hours, starting their business hours at about 11:00 am and closing later in the evenings at 9:00pm. However, the non-South Asian businesses tend to open their business early in the morning at about 8:00 am and close at 5:00pm. Once the non-South Asian restaurant closes, the South Asian businesses begin to attract most of their clientele.

This particular authentic restaurant has mostly been able to maintain its authenticity and cultural habitus, all the while attracting non-South Asian clientele. When asked about this dichotomy between this restaurant and its fellow authentic competitor restaurants, the interviewee indicated an important factor that significantly differed their authentic restaurant from the others, "The fact that we're willing to change, I think the mindset has a lot to do with it. They just have to change their approaches. They don't take advantage 
of the online presence". This suggests that the difference between a successful and unsuccessful authentic restaurant in the Little India business area is dependent on the understanding that changes must be made to the business approach.

\section{RESTAURANT 2}

Because restaurant 2 is located in a predominantly South Asian ethnic economy, it is imperative to question if this entrepreneur has modified their business approach. The owner mentions that efforts have been made in the past to cater to a different crowd by introducing an evening menu with a liquor license; however, it was not well received by the clientele. The business has established a particular style and habitus that they are known for and if they deviate away from that, similar to the authentic restaurants, their targeted clientele do not respond as well to it. The owner mentions that "People associated us too much with daytime and it [evening menu] didn't appeal". This is interesting to note because people have unconsciously accepted the habitus that this business has established for itself and it becomes clear that when they strive to deviate from that habitus to modify their business approach, it is not as well accepted by the clientele that frequent this business.

When questioning if changes were made to the business approach that would target specific clientele, the owner mentioned the addition of child friendly items on the menu. It is interesting to note that the additions made to the non-South Asian restaurant to target a specific clientele were those that helped cater to the needs of the current clientele. Conversely, the authentic South Asian restaurants are making changes that would help attract clientele that would not typically use their services (non-South Asian customers). 
As a result, perhaps the authentic restaurants understand the differences between their ethnic habitus and feel as though they must make the appropriate changes in order to continue running their business in an area that is frequented by a large non-South Asian population. Nonetheless, restaurant 2 does not seem to experience the pressure of attracting the South Asian clientele as they are meeting the needs of the majority residential population.

\section{ANALYSIS}

As I examine the way in which each restaurant defines its own cultural habitus, it is important to see if and how each business develops and makes modifications to their business practices and styles, and whether they are surrounded by co-ethnic businesses and clientele or not. To see an authentic South Asian restaurant go through changes to successfully keep up with the changing nature of the business may be perceived as an approach that takes away from their authenticity. However, restaurant 1 has found a good balance between maintaining the taste and most of the presence of an authentic establishment. At the same time, it changed its approach to marketing to ensure that they can appeal to clientele who are less familiar with the authentic South Asian culture and ethnic habitus. As a result, it is seen that these subtle cultural changes, although difficult to implement by many South Asian business owners who are unaware of their benefits, has been quite helpful in the survival of this authentic restaurant. It is unfortunate that so many purely authentic restaurants located in Little India have gone unnoticed by the clientele in the area and, as mentioned by the business owner, it seems that their inability to deviate from their traditional business approaches becomes problematic in attracting customers that do not share their ethnic habitus. 
Conversely, the non-South Asian restaurant did not face issues with cultural business modifications in trying to cater to a clientele that did not associate with their established habitus. Perhaps because the overall presentation and the group of people that this restaurant targets is widely representative of the surrounding residential population, there is not a necessary need for modifications. While the restaurant owner indicated that, in the past, they have tried to incorporate themselves to the South Asian culture by participating in events such as the South Asian festival, they were not very well recognized. However, this is a festival targeted to celebrating South Asian culture and attendees may be more inclined to embrace that by visiting South Asian focused businesses. Nonetheless, upon observation, it is clear that there is not a predominant South Asian based clientele frequenting this restaurant. When discussing changes made to cater to a specific clientele, the owner mentions modifications that would better serve its existing customers, motivating them to keep coming back. This further reinforces the idea that the non-South Asian habitus, which has been developed as part of the business approach, has been quite successful for this business in trying to attract clientele to the restaurant.

As Little India goes through gentrification and more non-South Asian residents and their family members move into the area, the overall ethnic habitus of this location also experiences redevelopment. This change in the surrounding social field is the result of varying practices, styles, and tastes that are being introduced to the once predominantly South Asian business area. Therefore, through observation, interviews, and analysis of authentic and non-authentic restaurants in the area, it is suggested that authentic South 
Asian restaurants should engage in modifying their business development and cultural habitus in trying to cater to a diverse clientele.

\section{Chapter 5: CONCLUSION}

This research has provided insight on how ethnic business owners negotiate their habitus and cultural practices in business development, whilst conducting business in a gentrifying area. Through analyzing an authentic South Asian restaurant and a non-South Asian restaurant in a gentrifying business area, this research has found that an authentic South Asian restaurant is making changes to their presentation and habitus in trying to attract both South Asian and non-South Asian clientele. These changes to the habitus can be related to Pierre Bourdieu's theoretical focus on the habitus and his opposition to essentializing culture. Although South Asian migrant business owners may make changes, it is clear that maintaining their authenticity and preservation of culture is imperative to their business approach. As a result, these changes to the habitus are done in a strategic manner that allows ethnically focused businesses to embrace their culture, all the while selling their exoticism in a way that is accepted by the surrounding nonSouth Asian clientele. In comparison, the non-South Asian restaurant did not experience the same need to make changes to their business development and overall cultural habitus as their target clientele consisted of the gentrifying community. Nonetheless, it was interesting to see that despite these cultural and business differences, both these restaurant owners exhibited similarities in the motivation behind their business development and the overall notion of success. 
This research helps contribute to current literature in several ways. In a study by Hiebert, Rath, \& Vertovec (2015), the authors discuss the role of market interaction between a dominant culture and the corresponding minority culture group, indicating that there has not been a theoretical perspective presented on how these two groups work with one another and the outcomes that arise from mixing two groups with differing cultures together. This study strives to close this gap in literature by examining Bourdieu's theoretical perspective of the habitus in analyzing the role of varying cultures working amongst each other in an ethnic economy and exploring how their respective cultures are negotiated in the process. By being geographically close to a dominant gentrifying population that does not share a South Asian cultural capital, South Asian business owners may choose to redevelop their ethnic businesses in a way that helps attract this population while celebrating their own authenticity in also appealing to the needs of their South Asian clientele. In addition, Bauder (2005) also indicates that there is a gap in the ethnic economies literature in that there is a lack of empirical research in connecting the unique cultural practices of migrant employment to their respective habitus. This research provides empirical data that specifically examines the role of the habitus in linking cultural practices and the business development strategies used by self-employed migrants.

Further research on the topic of ethnic economies and the impact of gentrification and redevelopment can focus on other communities such as the Danforth Greektown or Chinatowns located across downtown Toronto. It would be interesting to research ethnic economies that have a corresponding ethnic residential community, obtaining a better 
understanding of the extent in which ethnic businesses in these areas present their authentic cultural habitus in business development.

\section{Limitations}

I had initially planned to include three restaurants in my sample, with the third being a South Asian restaurant that strives to sell its exoticism while marketing itselves in a way that would be favourable to the gentrifying community. However, despite persistent attempts of contacting the restaurants that matched this criterion, I was unable to meet with the restaurant owners to discuss the study and obtain consent in time to complete this major research paper. Nonetheless, I am trying to conduct the observation and interviews for this third restaurant, to supplement the data I have gathered for the two restaurants and to help enhance my study for potential future publications. 


\section{APPENDIX}

Interview questions of owners/managers based on research questions

\section{A) What are the different looks, practices, styles, and tastes prevalent amongst these carefully selected restaurants in Little India?}

1. Briefly describe your business.

2. Why have certain items been placed on the menu? (Researcher would tailor question based on observations)

3. Why have you decided to decorate in this specific way? Is it symbolic?

4. How do you feel about the surrounding businesses in the area?

5. What kind of changes have you observed in the neighbourhood?

B) Do the styles and tastes projected by the restaurants ethnic habitus have an impact on how ethnic businesses fare? The ethnic habitus can be further measured through the interaction with customers, taste, and styles, and determine which practices have rendered successful.

1. Why have you chosen this particular location in Little India?

2. What has motivated you to continue running your business in the area?

3. What have been your key successes*?

* It is very important to problematize the notion of success as it is a subjective term and for some it may mean financial gain while for others it may be seen as a family business. Therefore, business owners may have a different reasoning for engaging in their business ventures. As a result, this question will be asked to indirectly address the notion of success, without assuming a specific definition for success, specifically determining how the business owners, themselves, would define this term.

\section{C) Are entrepreneurs able or unable to modify their business practices, styles, etc.?}

1. Have you modified your business approach? If so, why?

2. Have you felt the need to make changes to your business approach in targeting a specific clientele?

3. What changes have affected your business development? Discuss the changes that you may/may not have made.

4. What kind of changes have you observed in the clientele? Have you made changes to your business to reflect these changes? 


\section{REFERENCES}

Alraouf, A. A. 2010. Regenerating urban traditions in Bahrain. Learning from Bab-AlBahrain: The authentic fake. Journal of Tourism and Change, 8(1-2), 50-68.

Amdur, L., et. al. 1992. Artists and immigrants in New York City restaurants. In Zukin, S. (Eds.), The Cultures of Cities. UK: Blackwell Publishers.

Bagwell, S. 2008. Transnational family networks and ethnic minority business development. International Journal of Entrepreneurial Behaviour and Research, 14(6), 377-394.

Bateman, C. November 30, 2014. What Little India used to look like in Toronto. BlogTO.http://www.blogto.com/city/2014/11/what_little_india_used_to_look_like_in _toronto/

Bauder, H. 2005. Immigrants' attitudes towards self-employment: The significance of ethnic origin, rural and urban background and labour market context. Research on Immigration and Integration in the Metropolis Working Paper Series, No. 05-13.

Bauder, H. 2006. Labor movement: How migration regulates labor markets. New York: Oxford University Press.

Bauder, H. \& Suorineni, A. 2010. Toronto's Little India: A brief neighbourhood history. Toronto: Ryerson University.

Bauder, H. \& Ritchie, I. 2011. Toronto's Little India in Residential Context: A geographical analysis of census data. Toronto: Ryerson University.

Burton, I. 1963. A restatement of the dispersed city hypothesis. Annals of the Association of American Geographers, 53, 285-289.

Hudson, A. (June 16, 2015). Dinner and a movie the start of the Gerrard India bazaar. Beach Metro: http://www.beachmetro.com/2015/06/16/dinner-movie-start-gerrardindia-bazaar/

Bonacich (1999). Class approaches to ethnicity and race. Critical Sociology, 25(2/3): 166-194.

Bonacich \& Modell, (1980). The economic basis of ethnic solidarity: small business in the Japanese American Community. Berkeley: University of California Press.

Bourdieu, P. 1990. The Logic of Practice. Stanford: Stanford University Press.

Bourdieu, P. 1986. The Forms of Capital, in J.G. Richardson (ed.) Handbook of Theory and Research for the Sociology of Education, pp. 241-59. New York: Greenwordpress.

Bourdieu, P. 1984. Distinction: A Social Critique of the Judgement of Taste, trans. Rice, R. Cambridge, MA: Harvard University Press. 
Bourdieu, P. 1977. Outline of a Theory of Practice. Cambridge University

Press.Creswell, W. J. 2007. Qualitative inquiry \& research design: Choosing among five approaches. Thousand Oaks, CA: Sage Publications

Bourdieu, P. 1998. Practical Reason: On the Theory of Action. Stanford, CA: Stanford University Press.

GIBBIA. 2015. Gerrard India Bazaar. http://www.gerrardindiabazaar.com/

Casey, E.S. 2001. Between geography and philosophy: What does it mean to be in the place-world?, Annals of the Association of American Geographers 91, 683-697.

Cook, I. 2008. Geographies of food: Mixing progress. Human Geography 32(6), 821833.

Cwiertka, K. J. (2005) From ethnic to hip: Circuits of Japanese cuisine in Europe. Food and Foodways 13(4): 241-272.

DECA (Danforth East Community Association). 2015. The Pop-up Shop Project. http://deca.to/pop-up/

Erel, U. 2010. Migrating cultural capital: Bourdieu in migration studies. Sociology, 44(4), 642-660.

Hackworth, J. \& Rekers, J. 2005. Ethnic packaging and gentrification: The case of four neighbourhoods in Toronto. Urban Affairs Review, 41(2), 221-236.

Hiebert, D., Rath, J., \& Vertovec, S. 2015. Urban markets and diversity: Towards a research agenda. Ethnic and Racial Studies, 38(1), 5-21.

King, A. 2004. Spaces of Global Cultures: Architecture, Urbanism, Identity. Routledge: New York.

Kumar, S. \& Martin, G. 2004. A case for culturally responsive urban design. Ontario Planning Journal, 19(5), 5-7.

Ley, D. 1999. Myth and meaning of immigration and the metropolis. Canadian Geographer, 43(1), 2-19.

Ley, D. 2003. Seeking homo economicus: The Canadian state and the strange story of the business immigration program. Annals of the Association of American Geographers, 93(2), 426-441.

Ley, D. 2005. Indicators of entrepreneurial success among business immigrants in Canada. Research on Immigration and Integration in the Metropolis Working Paper Series, No. 05-01. 
Li, P. S. 2001. Immigrants propensity to self-employment. IMDB Research Paper Series.

Light, I., Sabagh, G., Mehdi, B., \& Der-Martirosian, C. 1994. Beyond the ethnic enclave economy. Social Problems, 41(1), 65-80.

NHS Census Data. 2011. Greenwood-Coxwell Neighbourhood Profile. http://www1.toronto.ca/wps/portal/contentonly?vgnextoid=a9ebb3d0122c1410VgnVC M10000071d60f89RCRD\&vgnextchannel=cf8a42f18beb2410VgnVCM10000071d60 f89RCRD

Kaminer, M. September 7, 2014. For Toronto's Little India, a New Crowd. New York Times. http://www.nytimes.com/2014/09/07/travel/for-torontos-little-india-a-newcrowd.html?_r=3

Oliver, C. \& O'Reilly, K. 2010. A Bourdieusian analysis of class and migration: Habitus and the individualizing process. Sage, 44(1): 49-66.

Paez, S. B. (January, 22, 2014) Saving Little India. The Origami. http://theorigami.ca/2014/01/22/saving-india/

Portes, A. 1981. Modes of structural incorporation and present theories of labor immigration.' In Global Trends in Migration, eds. Mary Kritz, Charles B. Keeley, and Silvano Tomasi, 279-297. New York: Center for Migration Studies.

Pottie-Sherman, Y. \& Hiebert, D. 2015. Authenticity with a bang: Exploring suburban culture and migration through the new phenomenon of the Richmond Night Market. Urban Studies, 52(3), 538-554.

Suorineni, A. 2010. Gerrard India Bazaar: An atypical ethnic economy in a residential neighbourhood. MRP; Ryerson University.

Walton-Roberts, M. \& Hiebert, D. 1997. Immigration, entrepreneurship, and the family: Indo-Canadian enterprise in the construction industry of greater Vancouver. Canadian Journal of Regional Science, 2(12), 119-140.

Zhuang, Z. C. 2013. Rethinking multicultural planning: An empirical study of ethnic retailing. Canadian Journal of Urban Research, 22(2), 90-116.

Zukin, S. 2009. Changing landscapes of power: Opulence and the urge for authenticity. International Journal of Urban and Regional Research, 33(2), 543-553. 